\title{
Genesis of the Chickasha, Oklahoma, Tornado on 24 May 2011 as Observed by CASA Radar and Oklahoma Mesonet
}

\author{
JERALD A. BROTZGE \\ University at Albany, SUNY, Albany, New York \\ CYNTHIA MORGAN LUTTRELL \\ University of Oklahoma, Norman, Oklahoma
}

(Manuscript received 24 April 2014; review completed 26 March 2015)

\begin{abstract}
On the afternoon of 24 May 2011, a dozen tornadoes formed across central Oklahoma that included one EF-5 and two EF-4 tornadoes. One of the EF-4 tornadoes developed in the city of Chickasha, Oklahoma, and was well sampled by a nearby Collaborative Adaptive Sensing of the Atmosphere (CASA) X-band radar. Located within $3 \mathrm{~km}$ range, the CASA radar obtained low-level ( 100 m AGL), high-spatial ( 100 m), hightemporal $(60 \mathrm{~s})$ sampling data at the time of tornadogenesis. In addition, an associated boundary was sampled by two Oklahoma Mesonet sites located within $5 \mathrm{~km}$ of tornadogenesis. Analyses of the radar imagery and surface data revealed that interaction of the boundary with the low-level mesocyclone may have contributed to tornado initiation. The coiling boundary and subsequent tornadogenesis were not sampled by the nearest WSR-88Ds (located $70 \mathrm{~km}$ and $119 \mathrm{~km}$ away). This event demonstrates how local, supplementary sensor networks, such as high-resolution radars and surface mesonets, can improve situational awareness and confidence for the operational forecaster during a hazardous weather scenario.
\end{abstract}

\section{Introduction}

The current Weather Surveillance Radar-1988 Doppler (WSR-88D) network provides adequate spatial and temporal resolution for observing most precipitation systems and their related mesoscale phenomena. However, misoscale features (40-500 m in scale) cannot be observed directly at the time and space scales needed for routine warning operations. Indeed, critical precursors of tornadogenesis, such as rear-flank downdrafts (RFDs), may be missed owing to the coarse sampling of the WSR-88Ds, and the relatively long distance between radars limits coverage below $3 \mathrm{~km}$ AGL (Westrick et al. 1999; Maddox et al. 2002). The average spacing between radars east of the Rocky Mountains is $230 \mathrm{~km}$ (McLaughlin et al. 2009). Alternative or supplementary sensing systems, such as gap-filling radars or local surface networks with relatively high-sampling frequency and resolution, have been shown to improve short-term, mesoscale prediction (Schenkman et al. 2011a, 2011b; Snook et al. 2011, 2012). Likewise, supplementary data may aid operational forecasters with improved situational awareness and more precise warning capability. The purpose of this paper is to highlight one example where data from a mix of supplemental (non-federally owned) sensors provided detailed local environmental information just prior to tornadogenesis.

One of the primary challenges for operational forecasters charged with issuing tornado warnings is detecting when and where tornadogenesis will occur. This task is made easier with the identification of tornado precursors. Supercell downdrafts are known to be crucial for tornadogenesis, but they are a ubiquitous aspect of supercells and therefore their presence alone tells us little about the prospects for tornadogenesis. There is evidence that relatively warm (though typically still negatively buoyant) downdrafts may contribute to tornadogenesis (Markowski 2002; Markowski et al. 2002; Grzych et al. 2007). More recently, field observations have shown that localized enhancements of rear-flank outflow and sudden 
cascades of precipitation from aloft on the rear flank sometimes immediately precede the intensification of near-ground rotation (Lee et al. 2012; Kosiba et al. 2013; Snyder et al. 2013). Moreover, complex stormscale interactions with additional boundaries, colliding low-level boundaries, and storm mergers also can influence the intensity or demise of parent storms and affect subsequent tornadogenesis (e.g., Markowski et al. 1998; French et al. 2014). Unfortunately, many of these finer-scale features often remain undetected with the conventional (federally operated) observing network (e.g., automated surface observing systems, WSR-88Ds, etc.).

During the afternoon and evening of 24 May 2011, a dozen tornadoes were reported across central Oklahoma, with seven of those being EF-2 or greater (including one EF-5 and two EF-4s). One of those EF4 tornadoes initiated in the city of Chickasha at 2209 UTC. The tornado remained on the ground for nearly an hour, moving northeast across three counties with a total path length of $53 \mathrm{~km}$, killing one, and injuring 48 [National Weather Service (NWS 2014)]. Fortuitously, an experimental X-band (3-cm wavelength) radar was located in Chickasha within $3 \mathrm{~km}$ of tornado initiation and recorded data at high spatial $(\sim 100 \mathrm{~m})$ and temporal $(\sim 60 \mathrm{~s})$ sampling at the time of tornadogenesis. Two nearby weather stations also recorded in situ surface data of a low-level boundary that may have played a role in tornado initiation. Data from this event confirm previous results from experimental mobile radars of boundaries interacting with low-level mesocyclones (e.g., Markowski et al. 1998). However, this case offers promise that such data could be observed more routinely if and when additional, nonfederal observing networks are integrated into weather service operations. As an example of how information from supplemental networks could be used, this article reviews the data collected on 24 May 2011 and explores the properties and movement of a subtle, lowlevel boundary that may have contributed to tornadogenesis.

\section{Data and methods}

The Center for Collaborative Adaptive Sensing of the Atmosphere (CASA; McLaughlin et al. 2009) project was founded in 2003 by the National Science Foundation as an engineering research center with the goal to improve low-level sensing using the development of low-cost, low-power, X-band weather radars that could either replace or supplement existing radar networks. CASA prototype (and similarly designed Xband) radars can provide real-time adaptive scanning at high temporal $(60 \mathrm{~s})$ and spatial $(\sim 100 \mathrm{~m})$ sampling (Bharadwaj et al. 2010), and networks of these radars can be used to fill gaps in low-level coverage. [For a detailed list of CASA radar specifications, see Junyent et al. (2010).] To test and demonstrate this technology, a 4-node network of CASA radars was deployed in southwestern Oklahoma, roughly midway between two WSR-88Ds [Frederick (KFDR) and Twin Lakes (KTLX); Junyent et al. 2010]. The CASA testbed operated between 2006 and 2011, and included four radars located in or near the cities of Cyril, Lawton, Rush Springs, and Chickasha. During that time, six tornadoes were observed, including the one detected on 24 May 2011.

The CASA radars collected data in an automated, adaptive fashion (Brotzge et al. 2010). The radars started a new scan cycle every $60 \mathrm{~s}$. During that time, the radars either completed three $360^{\circ}$ scans at lowlevels $\left(1,2\right.$, and $3^{\circ}$ elevation) or finished one $360^{\circ}$ scan at the $2^{\circ}$ elevation followed by sector scans of varying width. This "adaptive scan" started at $1^{\circ}$ elevation with continued scanning at higher elevations $\left(\sim 3,5,7,9,11\right.$, and $\left.14^{\circ}\right)$ until the 60 -s scanning cycle completed. Only the $360^{\circ}$ scans at $2^{\circ}$ elevation are shown in this case analysis.

All radar data were archived on tape. Extensive quality control was applied within the radar processing, including clutter mitigation and correction to the reflectivity from signal attenuation along the radial beam (Bharadwaj et al. 2010; Junyent et al. 2010). For this case study, all radar data were plotted using the Warning Decision Support System-Integrated Information (WDSS-II) software (Lakshmanan et al. 2007).

To better understand the boundary associated with tornadogenesis in this case, 1-min data were collected from two nearby Oklahoma Mesonet sites, located near Ninnekah (NINN) and Chickasha (CHIC). The boundary moved from south to north directly over both mesonet sites just minutes prior to tornadogenesis.

The Oklahoma Mesonet is a network of 120 automated environmental monitoring stations deployed evenly across the state of Oklahoma (Brock et al. 1995; McPherson et al. 2007). One or more stations are located in each of Oklahoma's 77 counties and measure temperature, relative humidity, wind speed, barometric pressure, rainfall, solar radiation, and soil moisture and temperatures. Temperature and relative humidity are measured at $1.5 \mathrm{~m} \mathrm{AGL}$, and wind speed 
and direction are measured at $10 \mathrm{~m}$ AGL. Pressure is sampled every $12 \mathrm{~s}$, while all other above-ground measurements are taken every $3 \mathrm{~s}$ and then averaged over 5-min intervals. Whereas the standard mesonet data are averaged into 5-min samples, 1-min averaged data are collected and temporarily stored at each site (McPherson et. al 2007). In this case, the 1-min data from these two sites were downloaded manually shortly following the tornado. Figure 1 shows the two mesonet sites and the WSR-88D and CASA radar locations relevant to this study.

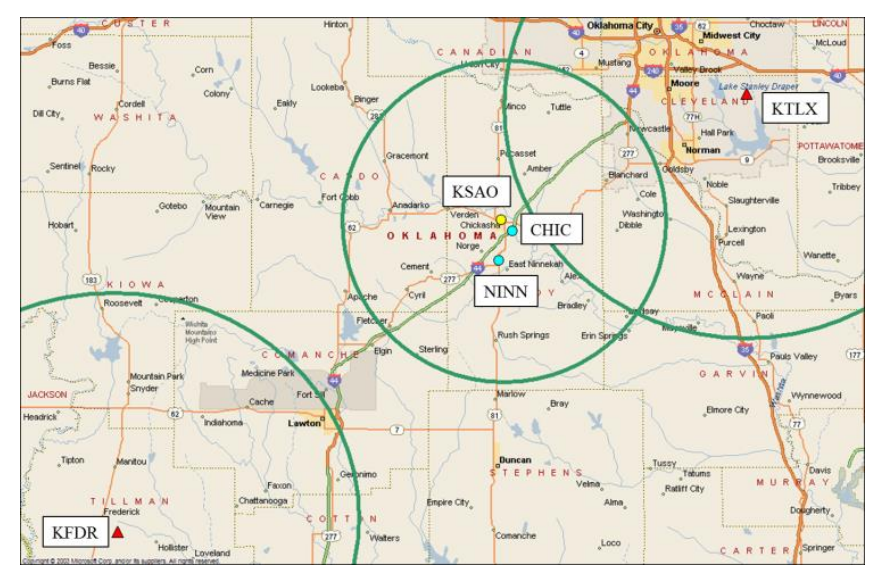

Figure 1. Map of southwestern OK showing the locations of two nearby WSR-88Ds (KFDR and KTLX, as indicated by the red triangles) and two nearby OK Mesonet sites (CHIC and NINN, as indicated by the blue circles). The CASA radar (KSAO) location is shown by the yellow circle. A 40-km range ring is drawn around the CASA radar, and a 60-km range ring is drawn around each of the WSR-88D radars. Click image for an external version; this applies to all figures hereafter.

\section{Radar and mesonet analysis}

\section{a. Synoptic and mesoscale setting}

At 1200 UTC 24 May 2011, an amplifying shortwave trough was over the western United States. A surface low pressure center had formed in the Texas Panhandle, with a cold front surging south and east to the west of the low. A dryline extended east and south from the low pressure center, along the western Oklahoma border with Texas. By 1700 UTC, a low-level jet of $15-20 \mathrm{~m} \mathrm{~s}^{-1}$ carried warm, moist air north into Oklahoma with a 500-mb speed maximum moving in from the west. According to the Storm Prediction Center (SPC) mesoscale analyses, mixed-layer convective available potential energy (MLCAPE) exceeded $3000 \mathrm{~J} \mathrm{~kg}^{-1}$ just east of the dryline across western Oklahoma, with $0-3-\mathrm{km}$ storm relative helicity increasing with time to $>450 \mathrm{~m}^{2} \mathrm{~s}^{-2}$. A Particularly Dangerous Situation (www.spc.noaa.gov/faq/\#2.7)
Tornado Watch was issued by the SPC at 1750 UTC for most of western and central Oklahoma and northern Texas, effective until 0300 UTC 25 May.

By 1900 UTC, a cluster of isolated cells had formed across western Oklahoma east of the dryline and were beginning to become severe. The first tornado warning was issued an hour later, at 2000 UTC, with the first confirmed tornado at 2020 UTC. Supercell thunderstorms approached the CASA testbed by 2100 UTC with a northeasterly storm motion of up to $22 \mathrm{~m} \mathrm{~s}^{-1}$.

\section{b. Supercell formation}

An intensifying storm approached the CASA radar (KSAO, see Fig. 1) located in Chickasha by 2200 UTC. This storm rapidly developed into a supercell as it neared Chickasha, as observed by both the Twin Lakes WSR-88D (KTLX; Fig. 2) and KSAO. A lowlevel (1 km AGL) circulation was first evident at 2157 UTC in the radial velocity data from KTLX, located approximately $70 \mathrm{~km}$ to the northeast. This circulation was coincident with the developing reflectivity appendage. Low-level convergence at $1 \mathrm{~km}$ AGL marked the leading edge of the appendage structure-just prior to tornadogenesis at 2209 UTC. An NWS tornado warning was issued for the storm at 2210 UTC.

\section{c. CASA radar imagery}

The KSAO CASA radar, located in downtown Chickasha, collected moment and polarimetric data simultaneous with KTLX but at a higher temporal and spatial resolution. KSAO provided greater resolution sensing at all elevations as well as new information of the storm structure below $1 \mathrm{~km}$. The CASA data revealed a subtle low-level ( $<1 \mathrm{~km}$ AGL) boundary that could not be seen by the WSR-88Ds, and which may have directly impacted tornadogenesis. The boundary was observed in the reflectivity and velocity data, but was more easily tracked in the polarimetric data.

At 2200 UTC segments of a thin, subtle surface boundary, located in the clear-air region just to the east of the supercell appendage, were observed in the CASA reflectivity and radial velocity data. The location of the boundary is highlighted by an offset yellow line in Fig. 3. The boundary moved slowly north, and was either formed or possibly influenced to some degree by moisture advecting north from a second storm located to its south. By 2206 UTC, the boundary was more clearly visible in the reflectivity, 


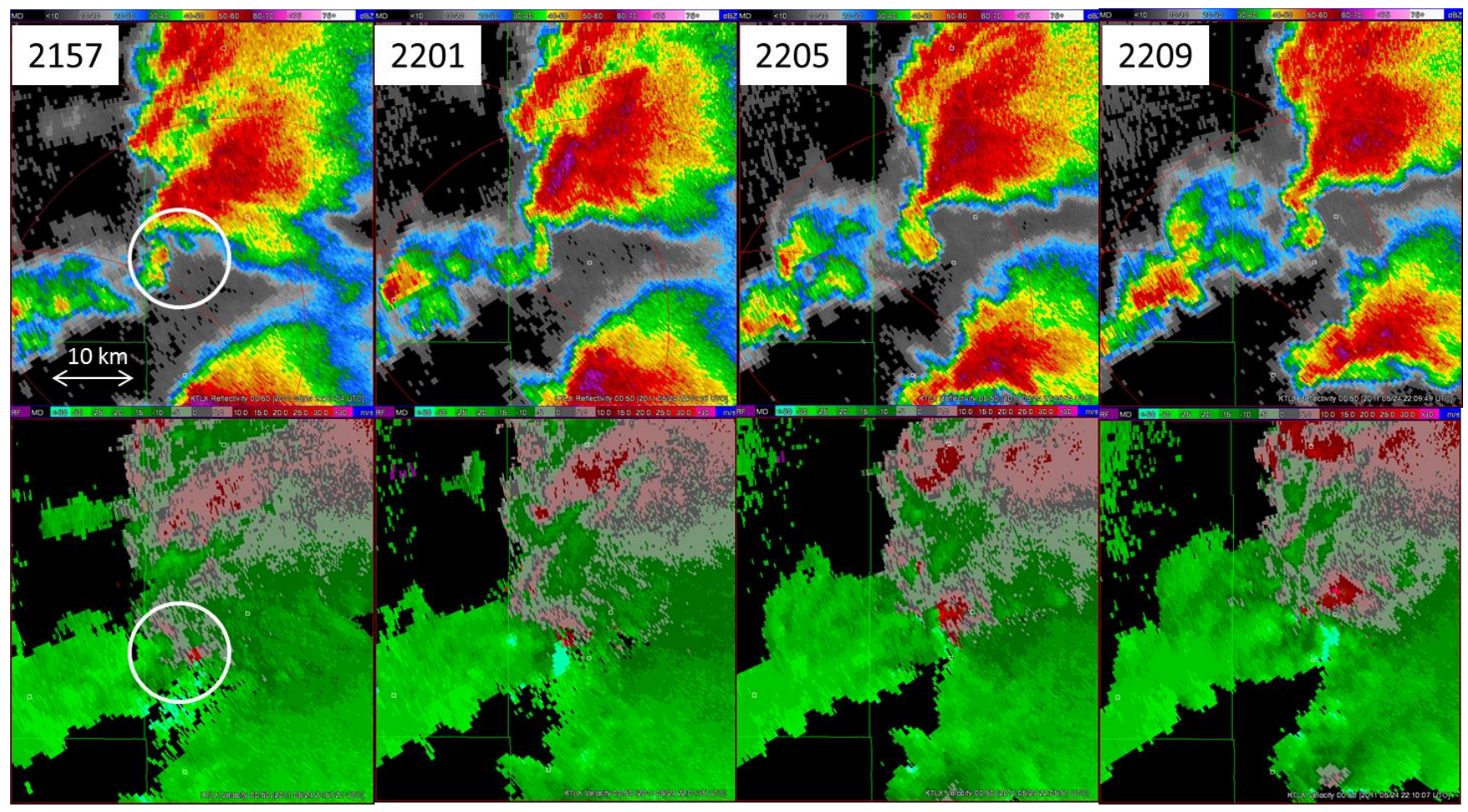

Figure 2. KTLX WSR-88D reflectivity (top) and radial velocity (bottom) at $0.5^{\circ}$ elevation between 2157 and 2209 UTC. The KTLX radar is located $70 \mathrm{~km}$ northeast of the storm of interest. A vortex is observed at $\sim 1.0 \mathrm{~km}$ AGL. Note the area of convergence marked within the white circle.

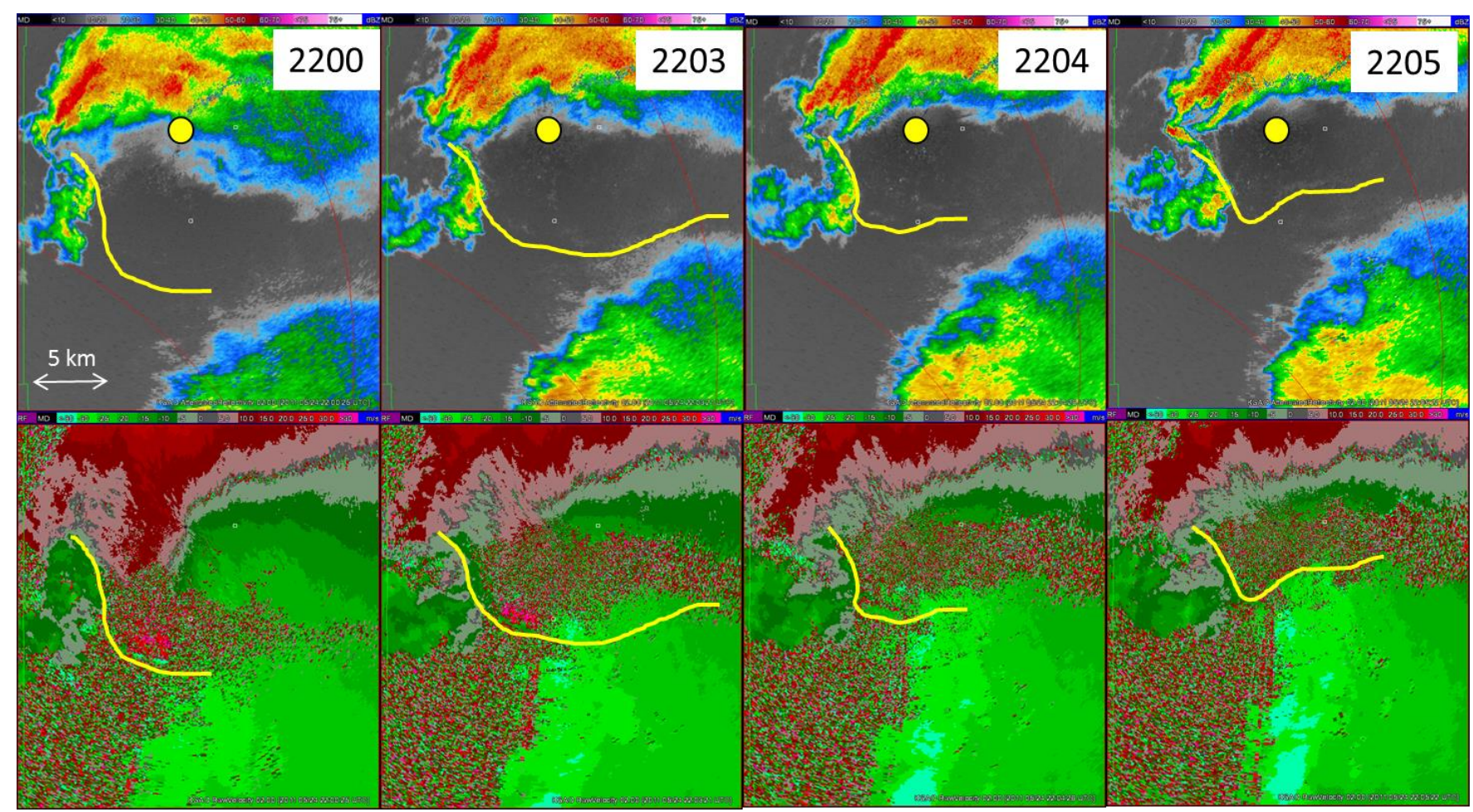

Figure 3. CASA (KSAO) reflectivity (top) and radial velocity (bottom) at $2.0^{\circ}$ elevation between 2200 and 2205 UTC. The location of a subtle convergence boundary is designated by a solid yellow line, offset slightly to the north of the boundary location. The radar location is designated by a solid yellow circle. 
$Z_{\mathrm{DR}}$, and $\rho_{\mathrm{hv}}$ (Fig. 4). Given the distinct signature in the polarimetric data, one may speculate that dust or biological targets were responsible for the echoes within the convergence line. Between 2206 and 2209 UTC, a coiled feature in reflectivity developed directly on the boundary, distorting the shape and orientation of the boundary in the process. A close-up image of reflectivity from both KTLX and KSAO at the time of tornadogenesis is shown in Fig. 5. The KTLX reflectivity was estimated to be at $\sim 900 \mathrm{~m}$ AGL near the area of tornadogenesis, whereas the KSAO reflectivity was at $100 \mathrm{~m}$ AGL. The detailed "T-structure," seen in the KSAO reflectivity at the tip of the coiled reflectivity feature, closely resembles the cyclonic and possible anticyclonic vortices from the dual-Doppler analysis of tornadogenesis presented by Kosiba et al. (2013). However, in this case, only cyclonic vorticity was observed in the radial velocity data from KSAO.

\section{d. Mesonet time series}

Although CASA radars were able to detect the low-level boundary, additional sensor information was needed to measure and understand the thermodynamic gradients associated with the convergence line. Data from two Oklahoma Mesonet sites provided in situ surface temperature, moisture, pressure, and wind data.

The boundary moved from south to north over NINN at approximately 2204 UTC (Fig. 6a). Prior to the boundary passage and beginning at 2140 UTC, the station pressure at NINN recorded two distinct highpressure pulses (Fig. 7a). The first pulse $(0.6 \mathrm{mb}$ at 2140 UTC) was followed by a second pulse $10 \mathrm{~min}$ later (1.5 mb at $2150 \mathrm{UTC})$. Each of these two highpressure peaks immediately preceded rainfall associated with the forward flank of the developing supercell as it moved northeast towards the site. These pressure peaks were followed by a significant drop in pressure of about $4 \mathrm{mb}$ at $\sim 2203$ UTC. The pressure trough coincided with the passage of the boundary as observed by KSAO.

A review of the potential temperature $(\theta)$ and virtual potential temperature $\left(\theta_{v}\right)$ noted a marked change in air mass with the approach of precipitation from the forward flank at 2143 UTC, with the air temperature dropping by nearly $2^{\circ} \mathrm{C}$. Nevertheless, the airmass temperature and moisture properties changed little with passage of the convergence line (Fig. 7b). However, the low-level winds did change (Fig. 7c). Surface winds veered from southeasterly at about $150^{\circ}$ ahead of the boundary to southwesterly at $240^{\circ}$ behind it, before settling back to about $180-200^{\circ}$ with the translation of the supercell to the east. Wind speeds peaked at about $19.5 \mathrm{~m} \mathrm{~s}^{-1}$ immediately after passage of the boundary, and the winds veered from south to southwest as the speeds diminished.

The boundary continued moving north, wrapping cyclonically around the mesocyclone, and crossed over CHIC at approximately 2208 UTC, only 4 min after crossing over NINN (Fig. 6b). By this time, the boundary was oriented southwest to northeast with the tornado already forming on the western end of it, as best judged from coincident CASA radar and damage survey data. A 3-mb pressure drop was recorded with boundary passage (Fig. 8a). Similar to NINN, the air temperature cooled at $\mathrm{CHIC}$ as the forward flank moved over the site, but $\theta$ remained fairly constant during the boundary passage (Fig. 8b). Because of the altered orientation, the surface winds at CHIC backed from $150^{\circ}$ to $90^{\circ}$ prior to and during the boundary passage (Fig. 8c), and wind speeds peaked briefly at that time.

Unlike the NINN site, the CHIC site was near the path of the tornado. Within 5 min after tornadogenesis, the tornado passed within $1 \mathrm{~km}$ directly southeast of CHIC. Between 2212 and 2214 UTC, the pressure dropped nearly $5 \mathrm{mb}$ from $957.1 \mathrm{mb}$ to $952.2 \mathrm{mb}$. The winds briefly increased in speed up to $18 \mathrm{~m} \mathrm{~s}^{-1}$ out of the north-northwest, before becoming westerly behind the mesocyclone.

\section{Discussion}

Because of the relatively few weather sensors operating in the vicinity of the supercell, the exact origin of the low-level boundary is difficult to determine. The boundary may have been an outflow boundary, an RFD gust front (RFDGF), or a merged hybrid of the two. The boundary may have started as a gust front generated by cold outflow air from the storm to the south. However, the surface data did not reflect the typical properties of a gust front (Karan and Knupp 2003). In this case, air temperature showed virtually no change with boundary passage, and while a modest pressure rise $(+0.5 \mathrm{mb})$ was noted as the boundary approached each site, the drop in pressure behind the boundary was much greater $(-4 \mathrm{mb})$. Furthermore, the strongest winds did not precede the boundary, but instead coincided with it. A second possibility is that the boundary was an RFDGF, wrapping cyclonically around the mesocyclone with time. However, the east- 


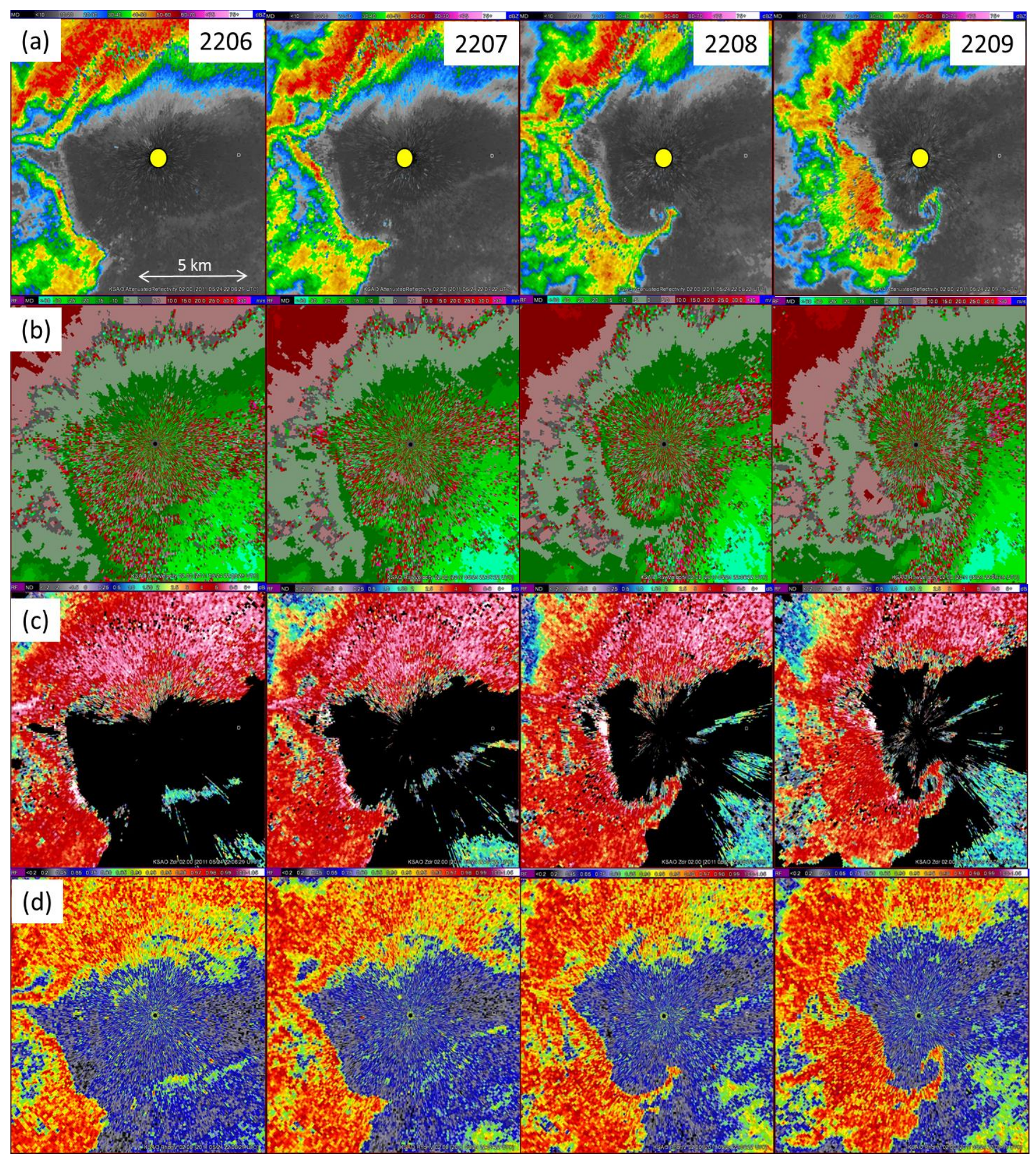

Figure 4. CASA (KSAO) (a) reflectivity, (b) radial velocity, (c) $Z_{\mathrm{DR}}$, and (d) $\rho_{\mathrm{hv}}$ at $2.0^{\circ}$ elevation between 2206 and 2209 UTC. The boundary discussed in the text and shown in Fig. 3 is more easily seen in both $Z_{\mathrm{DR}}$ and $\rho_{\mathrm{hv}}$. The radar location is designated by a solid yellow circle.

west orientation of the convergence line makes one suspicious of the hypothesis that the boundary originated from the storm of interest, and appears much more likely to have initiated externally from the storm. Indeed, the boundary parallels the northern edge of the storm to the south. 

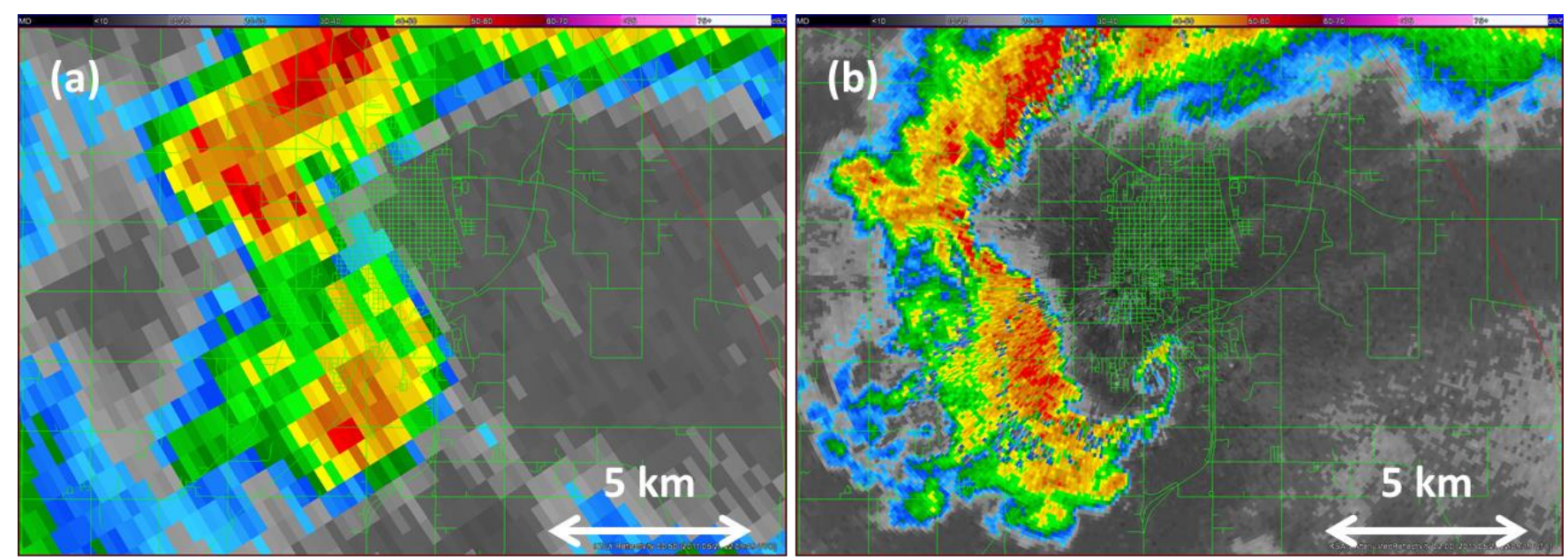

Figure 5. Radar reflectivity at 2209 UTC collected from (a) the nearest WSR-88D (KTLX) and (b) CASA radar (KSAO). The city street map of Chickasha is overlaid.
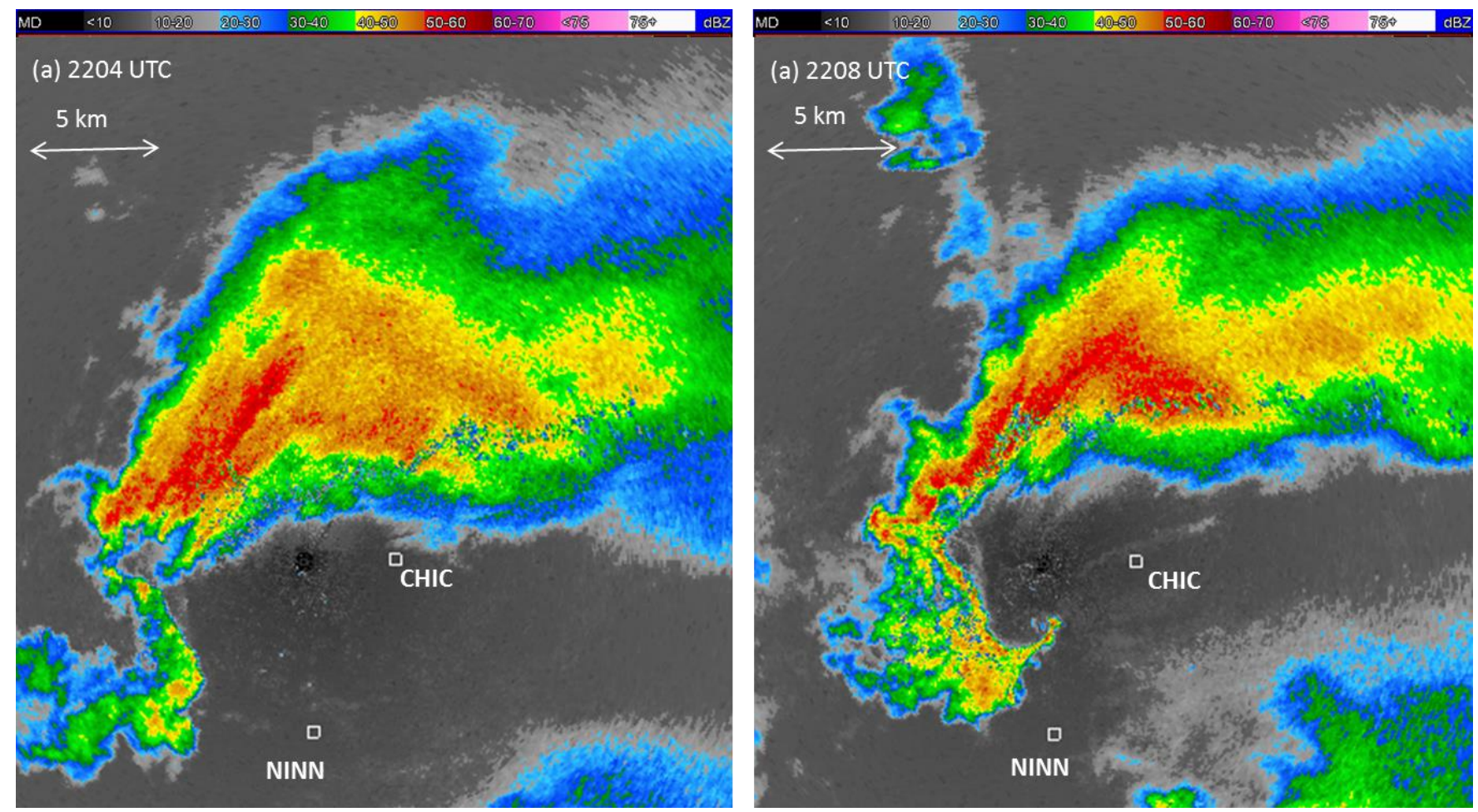

Figure 6. The reflectivity from KSAO collected at $2^{\circ}$ elevation at (a) 2204 UTC and (b) 2208 UTC. The OK Mesonet sites at Ninnekah (NINN) and Chickasha (CHIC) are labeled with white text.

\section{Conclusions}

WSR-88D, CASA radar, and surface mesonet sensors closely sampled a supercell, associated surface boundary, and developing vortex. The WSR-88D provided adequate coverage of the parent mesocyclone and storm evolution. An experimental CASA radar (KSAO), located in Chickasha, Oklahoma, was within $3 \mathrm{~km}$ of the developing tornado and provided low- level ( 100 m AGL), high-spatial (100-m gate spacing), and high-temporal (60-s updates) sampling of the evolving circulation. Two Oklahoma Mesonet sites (NINN and CHIC)-located within $7 \mathrm{~km}$ of tornadogenesis-provided detailed surface observations of an associated low-level boundary every minute. Several noteworthy aspects of this case study are listed below. 

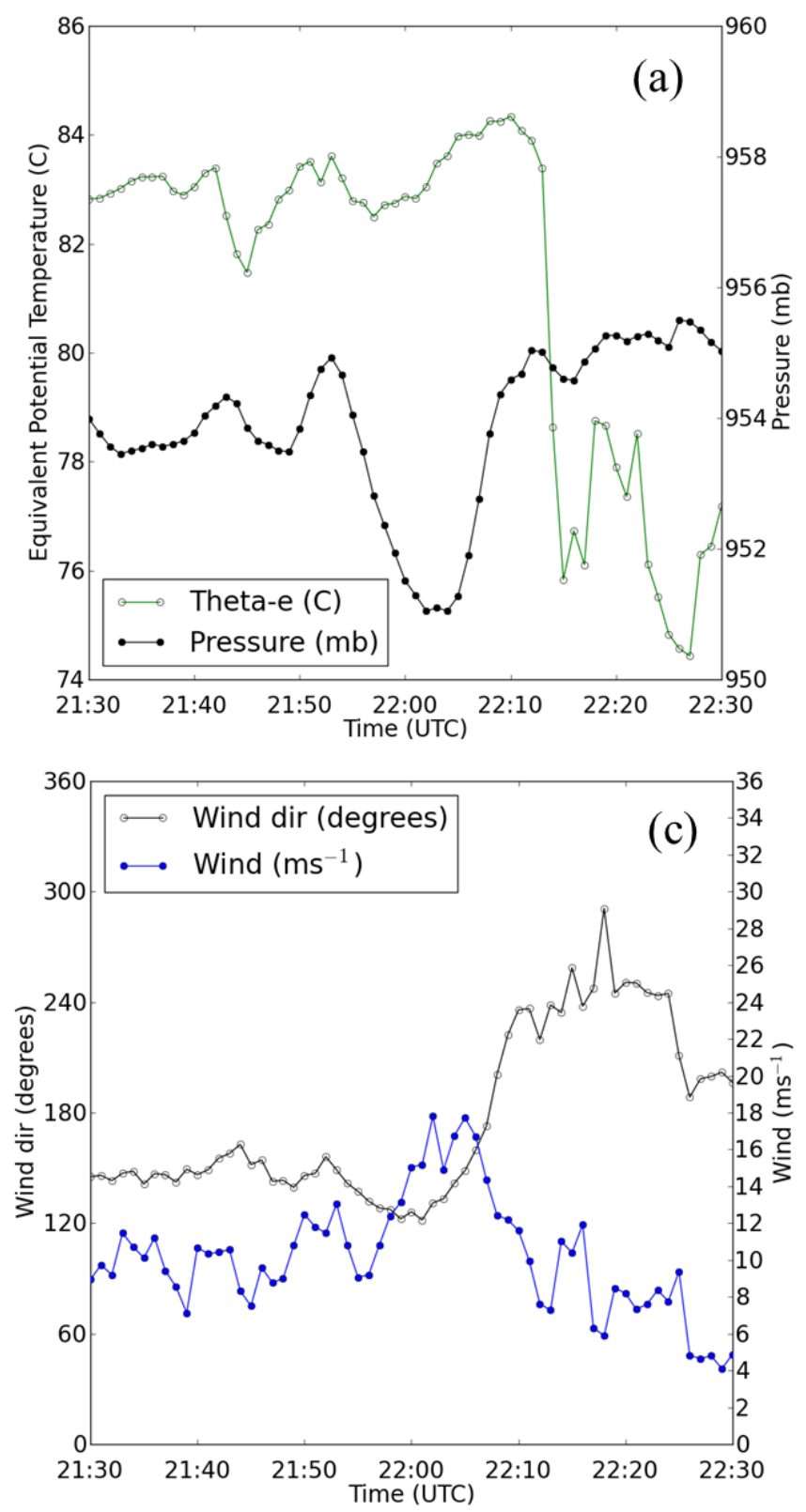

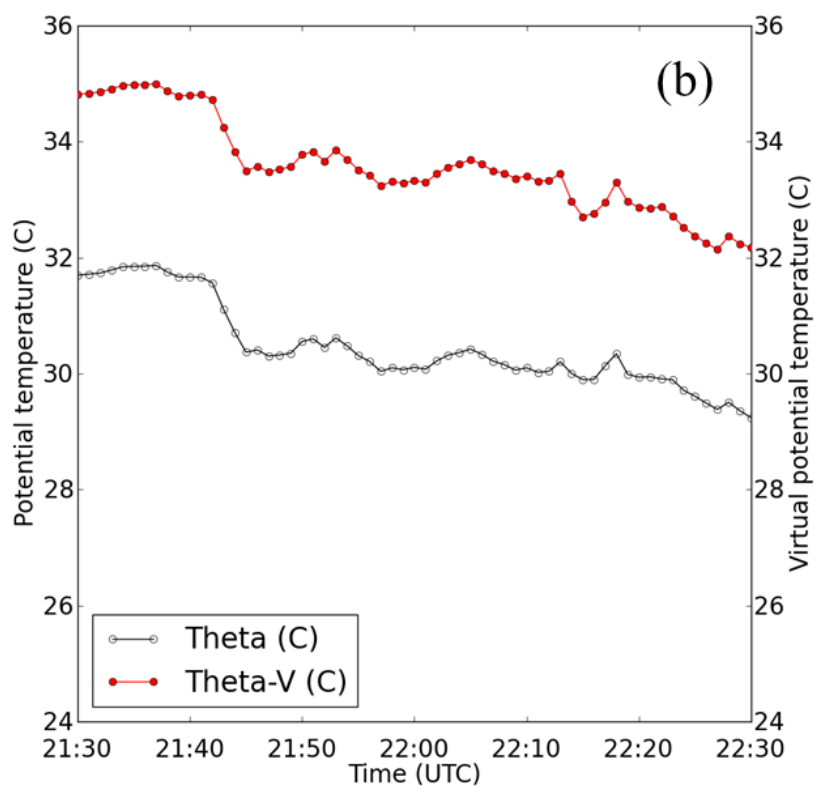

Figure 7. One-minute averages of (a) station pressure (mb) and equivalent potential temperature ( $\left.{ }^{\circ} \mathrm{C}\right),(\mathrm{b}) \theta$ and $\theta_{v}\left({ }^{\circ} \mathrm{C}\right)$, and (c) wind speed $\left(\mathrm{m} \mathrm{s}^{-1}\right)$ and direction $\left(^{\circ}\right)$ plotted for 2130 to 2230 UTC at the NINN mesonet site. Passage of the boundary over the site is estimated at 2204 UTC.

- Supplemental, local weather sensors augmented the federal network, thereby providing a more comprehensive detection system. In this case, a polarimetric, X-band radar sampled the area of tornadogenesis above $100 \mathrm{~m}$ AGL at very close range $(3 \mathrm{~km})$ with high-frequency sampling (storm volume scans once per minute). This provided an opportunity to examine storm structure and subsequent vortex development that otherwise would not have been observed. In addition, a related lowlevel boundary was sampled by sensors at two mesonet sites and observed by CASA radar. The low-level vortex was observed to form directly on the boundary. Even though the location and movement of the boundary was best observed within the radar polarimetric data provided by CASA, it was not detected by the WSR-88D. 

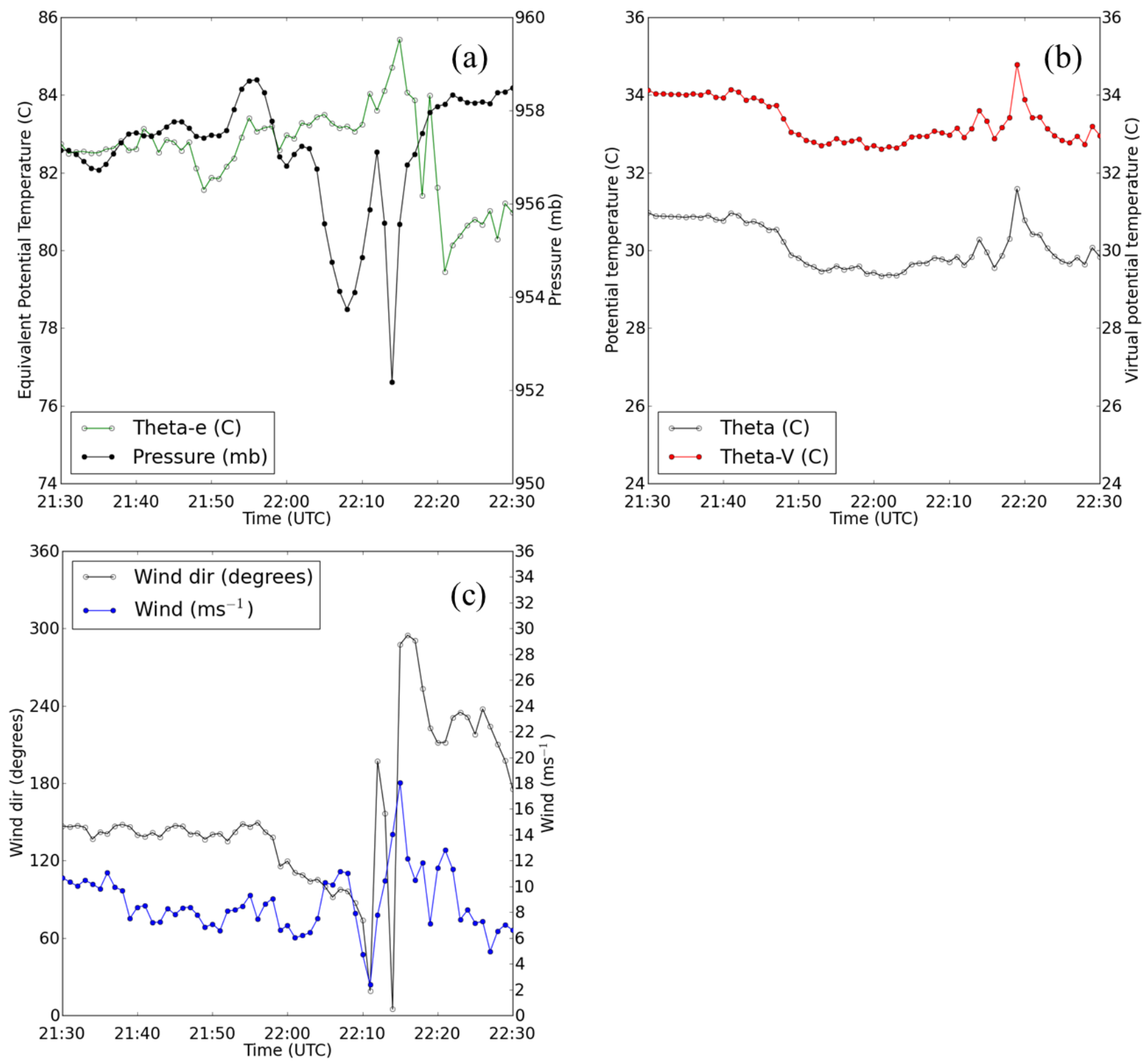

Figure 8. One-minute averages of (a) station pressure (mb) and equivalent potential temperature $\left({ }^{\circ} \mathrm{C}\right),(\mathrm{b}) \theta$ and $\theta_{v}\left({ }^{\circ} \mathrm{C}\right)$, and (c) wind speed $\left(\mathrm{m} \mathrm{s}^{-1}\right)$ and direction $\left(^{\circ}\right)$ plotted for 2130 to 2230 UTC at the CHIC mesonet site. Passage of the boundary over the site is estimated at 2208 UTC.

- In this event, surface temperature and moisture did not change at the mesonet sites with boundary passage. The $\theta$ of the storm inflow air was very similar to that behind the boundary. However, the low-level air cooled by nearly $2^{\circ} \mathrm{C}$ with passage of the storm's forward flank and remained nearly steady after that as the storm moved overhead. As suggested by Markowski et al. (2002), when air within an RFD is moderately warm compared to its environment, the additional lift from the relatively buoyant air within the RFD may contribute to tornadogenesis. Even though this boundary may not have originated from an RFD, one may speculate that the sustained, relatively warm air behind the boundary may have aided low-level vertical stretching - enhancing tornado development.

- In this case, tornadogenesis was more likely impacted by a change in the low-level winds that resulted from the passage of the convergence line. At NINN, winds backed slightly ahead of the boundary, but veered significantly behind it. At CHIC, southeasterly winds backed with time as the 
boundary orientation shifted from west-east to southwest-northeast. Wind speeds increased slightly at both sites with boundary passage. One may speculate about the impact of the interaction of strong low-level wind shear with the mesocyclone to initiate tornadogenesis.

For this particular tornado, the NWS tornado warning was issued one minute after tornadogenesis. Indeed, the NWS forecast office in Norman, Oklahoma, had real-time access to the CASA data and 5min mesonet data throughout the entire event. According to the science and operations officer at the time, the CASA data "were not critical to any warning decisions, but to observe the details of tornadogenesis was interesting and helped add some confidence in real-time" (D. Andra 2012, personal communication). Nevertheless, such fine attention to detail requires critical forecaster resources during a high-impact event. Proper balancing of time spent monitor-ing fine-scale details in high-resolution data and time spent on competing demands will become an increaseing challenge as the volume of observations available to NWS forecast offices continues to rise.

Acknowledgments. Thanks to Dr. Roger Brown (NSSL) for insightful discussions regarding this case, and Mr. Gregory Patrick (WFO Fort Worth, TX) and two anonymous reviewers for their helpful comments and suggestions in reviewing this manuscript. This work is supported by the Engineering Research Centers Program of the National Science Foundation under Award 0313747. Any opinions, findings, conclusions, or recommendations expressed in this material are those of the authors and do not necessarily reflect those of the National Science Foundation.

\section{REFERENCES}

Bharadwaj, N., V. Chandrasekar, and F. Junyent, 2010: Signal processing system for the CASA Integrated Project I radars. J. Atmos. Oceanic Technol., 27, 14401460, CrossRef.

Brock, F. V., K. C. Crawford, R. L. Elliott, G. W. Cuperus, S. J. Stadler, H. L. Johnson, and M. D. Eilts, 1995: The Oklahoma Mesonet: A technical overview. J. Atmos. Oceanic Technol., 12, 5-19, CrossRef.

Brotzge, J., K. Hondl, B. Philips, L. Lemon, E. J. Bass, D. Rude, and D. L. Andra Jr., 2010: Evaluation of distributed collaborative adaptive sensing for detection of low-level circulations and implications for severe weather warning operations. Wea. Forecasting, 25, 173-189, CrossRef.
French, M. M., H. B. Bluestein, I. PopStefanija, C. A. Baldi, and R. T. Bluth, 2014: Mobile, phased-array, Doppler radar observations of tornadoes at X band. Mon. Wea. Rev., 142, 1010-1036, CrossRef.

Grzych, M. L., B. D. Lee, and C. A. Finley, 2007: Thermodynamic analysis of supercell rear-flank downdrafts from project ANSWERS. Mon. Wea. Rev., 135, 240-246, CrossRef.

Junyent, F., V. Chandrasekar, D. McLaughlin, E. Insanic, and N. Bharadwaj, 2010: The CASA Integrated Project 1 networked radar system. J. Atmos. Oceanic Technol., 27, 61-78, CrossRef.

Karan, H., and K. Knupp, 2003: High resolution multisensor profiling of gust fronts. Preprints, 10th Conf. on Mesoscale Processes, Portland, OR, Amer. Meteor. Soc., 14.4. [Available online at ams.confex.com/ams/ pdfpapers/62734.pdf.]

Kosiba, K., J. Wurman, Y. Richardson, P. Markowski, P. Robinson, and J. Marquis, 2013: Genesis of the Goshen County, Wyoming, tornado on 5 June 2009 during VORTEX2. Mon. Wea. Rev., 141, 1157-1181, CrossRef.

Lakshmanan, V., T. Smith, G. Stumpf, and K. Hondl, 2007: The Warning Decision Support System-Integrated Information. Wea. Forecasting, 22, 596-612, CrossRef.

Lee, B. D., C. A. Finley, and C. D. Karstens, 2012: The Bowdle, South Dakota, cyclic tornadic supercell of 22 May 2010: Surface analysis of rear-flank downdraft evolution and multiple internal surges. Mon. Wea. Rev., 140, 3419-3441, CrossRef.

Maddox, R. A., J. Zhang, J. J. Gourley, and K. W. Howard, 2002: Weather radar coverage over the contiguous United States. Wea. Forecasting, 17, 927-934, CrossRef.

Markowski, P. M., 2002: Hook echoes and rear-flank downdrafts: A review. Mon. Wea. Rev., 130, 852-876, CrossRef.

, E. N. Rasmussen, and J. M. Straka, 1998: The occurrence of tornadoes in supercells interacting with boundaries during VORTEX-95. Wea. Forecasting, 13, 852-859, CrossRef.

, J. M. Straka, and E. N. Rasmussen, 2002: Direct surface thermodynamic observations within the rearflank downdrafts of nontornadic and tornadic supercells. Mon. Wea. Rev., 130, 1692-1721, CrossRef.

McLaughlin, D., and Coauthors, 2009: Short-wavelength technology and the potential for distributed networks of small radar systems. Bull. Amer. Meteor. Soc., 90, 1797-1817, CrossRef.

McPherson, R. A., and Coauthors, 2007: Statewide monitoring of the mesoscale environment: A technical update on the Oklahoma Mesonet. J. Atmos. Oceanic Technol., 24, 301-321, CrossRef.

NWS, cited 2014: The tornado outbreak of May 24, 2011. [Available online at: www.srh.noaa.gov/oun/?n=events20110524.] 
Schenkman, A. D., M. Xue, A. Shapiro, K. Brewster, and J. Gao, 2011a: The analysis and prediction of the 8-9 May 2007 Oklahoma tornadic mesoscale convective system by assimilating WSR-88D and CASA radar data using 3DVAR. Mon. Wea. Rev., 139, 224-246, CrossRef.

, and __, 2011b: Impact of CASA radar and Oklahoma Mesonet data assimilation on the analysis and prediction of tornadic mesovortices in an MCS. Mon. Wea. Rev., 139, 3422-3445, CrossRef.

Snook, N., M. Xue, and Y. Jung, 2011: Analysis of a tornadic mesoscale convective vortex based on ensemble Kalman filter assimilation of CASA X-band and WSR-88D radar data. Mon. Wea. Rev., 139, 34463468, CrossRef. and 2012: Ensemble probabilistic forecasts of a tornadic mesoscale convective system from ensemble Kalman filter analyses using WSR-88D and CASA radar data. Mon. Wea. Rev., 140, 21262146, CrossRef.

Snyder, J. C., H. B. Bluestein, V. Venkatesh, and S. J. Frasier, 2013: Observations of polarimetric signatures in supercells by an X-band mobile Doppler radar. Mon. Wea. Rev., 141, 3-29, CrossRef.

Westrick, K. J., C. F. Mass, and B. A. Colle, 1999: The limitations of the WSR-88D radar network for quantitative precipitation measurement over the coastal western United States. Bull. Amer. Meteor. Soc., 80, 2289-2298, CrossRef. 